can offer health professionals in rheumatology some theory and evidence-based methods to support PA maintenance in practice.

Disclosure of Interests: None declared

DOI: 10.1136/annrheumdis-2019-eular.8517

\section{SP0060 TOWARDS OPTIMAL INTENSITY}

George Metsios. University of Glasgow, Institute of Infection, Immunity, and Inflammation, Glasgow, United Kingdom

Background: There is ample evidence now to suggest that exercise can help ameliorate RMD symptoms and comorbidities. Similar to the prescription of medication, the dosage of exercise should be optimized to achieve the best health benefits. However, a consensus on the dosage of exercise prescription for RMD patients is currently missing.

Objectives: This talk will explore the data required from RMD patients to develop the best exercise prescription, exercise principles and current state-of-the-art, as well as how we can use the current evidence to identify the optimum dosage for the exercise prescription in people with RMDs

Methods: Suggestions have been synthesized using existing evidence-based resources, including recent systematic reviews and meta-analyses (EULAR, Cochrane Library and peer-reviewed journals publications) as well as randomized controlled trials. Data for the effectiveness of exercise dosage on various different outcomes has been extracted and will be explored.

Results: Different dosages of exercise have differing effects on symptoms of RMDs. The optimal dosage depends on various factors and on the outcome that the exercise prescription aims to improve.

Conclusion: Despite the increasing research on exercise in RMDs, a currently a consensus for the optimal exercise dosage is currently missing. More interdisciplinary research, with a heavy patient involvement, is required in the area.

Disclosure of Interests: None declared

DOI: 10.1136/annrheumdis-2019-eular.8537

THURSDAY, 13 JUNE 2019

13:30:00 - 15:00:00

\section{Getting a grip on the co-morbidities in gout}

\section{SP0061 GOUT AND ASSOCIATED CO-MORBIDITIES - RELEVANCE TO CLINICAL PRACTICE}

Edward Roddy. Keele University, Research Institute for Primary Care and Health Sciences, Keele, United Kingdom

Patients with gout very commonly have multiple co-existent comorbidities. Associations between gout and hypertension, obesity, chronic kidney disease and cardiovascular disease have long been recognised whereas several new comorbid disease associations, such as sleep apnoea and mental health problems, have been described more recently, including lower risk of neurodegenerative diseases. These associations are complex with some comorbidities such as obesity and sleep apnoea predisposing to the development of gout, whereas gout is a risk factor for incident cardiovascular disease and erectile dysfunction. The management of gout is often more complex in the presence of comorbidity and can present a significant therapeutic challenge. This talk will provide an update on the comorbidities that are associated with gout and discuss their implications for the management of gout, in particular for long-term urate-lowering therapy.

Disclosure of Interests: None declared

DOI: 10.1136/annrheumdis-2019-eular.8572

\section{SP0062 CARDIOVASCULAR MORBIDITY AND GOUT - FROM EPIDEMIOLOGY TO THERAPY}

Mariano Andrés. Hospital General Universitario de Alicante-ISABIAL, Sección de Reumatología, Alicante, Spain

Gout is an independent cardiovascular risk factor. Patients suffering from gout show a higher incidence of all forms of the atherosclerotic disease, as well as cardiovascular and all-cause mortality. This associates with both comorbidities and urate crystal-led inflammation. Thus, gout, along with being the most common form of inflammatory arthritis in rich countries, carries with significant morbidity and mortality. Proper management is essential. The purpose of this lecture is to analyze the potential strategies aimed to control the cardiovascular risk in patients with gout.

Disclosure of Interests: None declared

DOI: 10.1136/annrheumdis-2019-eular.8419
THURSDAY, 13 JUNE 2019

$13: 30: 00-15: 00: 00$

\section{Treatment is more than drugs}

\section{SP0063 NUTRITION AND RHEUMATIC DISEASES}

Elena Philippou. University of Nicosia, Life and Health Sciences, Nicosia, Cyprus

Background: Nutritional therapy could be a promising adjunct to pharmacological therapy in rheumatic disease (RMD).

Objectives: The aim of this talk is to provide evidence and recommendations on dietary management of rheumatoid arthritis, ankylosing spondylitis, systemic lupus erythromatosus, psoriatric arthritis and osteoarthritis.

Methods: Research studies, systematic reviews and recommendations associating diet and RMDs were identified through MEDLINE.

Results: Maintenance or achievement of a healthy body weight is central to RMDs since weight gain is common and often results as a side-effect of pharmacotherapy, further increasing inflammation. Adherence to the Mediterranean diet (MD) by consumption of plant-based foods such as wholegrains, legumes, fruit, vegetables, daily consumption of extra virgin olive oil, and reduced (monthly) consumption of red meat and desserts, is beneficial for all RMDs. The MD should be supplemented with extra omega-3 polyunsaturated fatty acids (PUFAs) and thus consumption of 'fatty fish' such as seabeam, seabass, trout, salmon, sardines or mackerel $\geq 2 /$ week, and walnuts, flaxseeds and chia seeds, daily is recommended, all providing different kinds of omega-3 fatty acids. The MD not only provides all the necessary vitamins and minerals with a balanced ratio of MUFA PUFA to reduce inflammation, but also has long term benefits on the cardiovascular system. Additional recommendations to manage high cholesterol, include the consumption of plant stanols/sterols, oats, unsalted nuts and soy protein and limiting intake of foods high in saturated and trans fats. It is also recommended that plasma Vitamin D concentration, important for bone and cartilage health, is assessed and a daily supplement is taken if necessary especially during the winter months. Additionally, it is important to consume enough calcium daily, this being equivalent to 3-4 glasses of milk or slices of cheese (preferably low in fat). Finally, evidence on possible relationships between RMDs and diet is limited and inconclusive and dietary restrictions are not recommended. In psoriatric arthritis, a gluten-free diet is recommended only in patients who test positive for serologic markers of gluten sensitivity. Use of unnecessary supplements should be avoided.

Conclusion: In conclusion, adherence to a healthy diet can aid in disease man agement in RMDs by reducing inflammation and the risk of cardiovascular disease.

\section{REFERENCES:}

[1] Aparicio-Soto M, Sánchez-Hidalgo M and Alarcon-de-la Lastra C (2017) An update on diet and nutritional factors in systemic lupus erythematosus management Nutrition Research Reviews 30:118-137

[2] British Dietetic Association (2017) Diet and Osteoarthritis. Available at: https://www.bda.uk.com/foodfacts/OsteoArthritis.pdf. Accessed: 1.3.19

[3] Ford AR, Siegel M, Bagel J, et al. (2018) Dietary Recommendations for AdultsWith Psoriasis or Psoriatic Arthritis From the Medical Board of the National Psoriasis Foundation: A Systematic Review. JAMA Dermatol. doi:10.1001/jamadermatol.2018.1412.

[4] Macfarlane TV, Abbood HM, Pathan E, et al. (2018) Relationship between diet and ankylosing spondylitis: a systematic review. European Journal of Rheumatology 5: 45-52.

[5] Petersson S*, Philippou E*, Rodomar C, Nikiphorou E. (2018) The Mediterranean diet, fish oil supplements and Rheumatoid arthritis outcomes: evidence from clinical trials. Autoimmunity Reviews 17(11):1105 (*joint first authors).

Disclosure of Interests: None declared

DOI: 10.1136/annrheumdis-2019-eular.8559

\section{SP0064 AKTIV-HOCH-R - COMBINING EXERCISE AND FUN}

Nicole Stefan-Schick. Deutsche Rheuma-Liga Bundesverband e.V., Physical activity, 53111 Bonn, Germany

Treatment is more than drugs: People with rheumatic diseases know about the health benefits of physical activity. But many studies show that integrating regular exercise into daily life is not always as easy as it seems, especially while experiencing rheumatic pain and feeling physical limitations.

Therefore the German Rheumatism League developed in association with leading experts in sports science and rehabilitation, at the Erlangen-Nürnberg University in Germany, "aktiv-hoch-r". 
"aktiv-hoch-r" is an evidence-based exercise programme which imparts knowledge of sports science and motivational aspects. So "aktiv-hoch-r" is not just about the physical exercises, but also includes educational aspects to the programme. The aim of "aktiv-hoch-r" is to inspire participants at an early stage to make a personal commitment to regular physical activity by helping them to understand the benefits for their long-term health. The programme should help them to self-motivate themselves to continue this for life.

To motivate people with rheumatic diseases to adopt an active lifestyle, "aktivhoch-r" uses a holistic approach, involving positive experiences of movement and playful tasks. The focus is on the individual capability of each participant.

So in "aktiv-hoch-r" classes participants learn how to move and how to exercise in a health-promoting way. They learn how to dose load in strength and endurance exercises. They also learn about the effects of regular physical activity on the body. There is a strong focus on self-efficacy, attitude and motivation: participants learn how to develop strategies to motivate themselves to do physical activity. This presentation provides some theoretical and practical insights into "aktivhoch-r".

Nicole Stefan-Schick

Sports Science consultant, Deutsche Rheuma-Liga Bundesverband e.V

Disclosure of Interests: None declared

DOI: 10.1136/annrheumdis-2019-eular.8593

THURSDAY, 13 JUNE 2019

13:30:00 - 15:00:00

\section{Challenging projects in education and training}

\section{SP0065 EULAR SCHOOL OF RHEUMATOLOGY 2019: A NEW ERA FOR EDUCATION}

Annamaria lagnocco. Academic Rheumatology Unit Universita degli Studi di Torino, Academic Rheumatology Centre, Turin, Italy

The first strategic aim of EULAR for the period 218-2023 is to be the leading provider of education in Rheumatic and Musculoskeletal Diseases (RMDs). The benefits that the rheumatology community gets from high levels of education in the field of RMDs result in an increased knowledge of them as well as in the optimization of their management. This leads to a significant relief to the lives of people with RMDs.

EULAR has traditionally been a strong supplier of education in rheumatology and the launch of the EULAR School of Rheumatology has further increased the EULAR's educational offering and its quality, by providing tailored learning materials, improving access to high quality education in the field of RMDs and developing innovative learning methods and recognised EULAR certifications.

The School of Rheumatology is as a fully integrated operational entity contained within EULAR which combines all educational offers, whether they are live courses, online courses, books, webinars or any other material, under one roof. In addition to the already existing offering, in the last years a team of experts in RMDs and with a solid experience in education has been working in the development of new activities and material addressed to rheumatologists, undergraduates, trainees, teachers, researchers, health professionals, and people with RMDs. Then, these new products, which integrate and further enrich the wide spectrum of existing offering, are tailored to the interests and fields of activity of different targets within the rheumatology community and are presented according to the most innovative educational methods. The use of a new learning management system which perfectly matches the current digital era, allows an optimized presentation and use of the new EULAR education opportunities.

With the modern and rapid developments of the Rheumatology discipline, the EULAR School of Rheumatology is today taking its educational offerings, services and products to a global audience worldwide.

Key Messages:

- The EULAR School of Rheumatology is an innovative educational model with new approaches, products and technologies which reflect the changing needs of the learners whether they are rheumatologists, undergraduates, trainees, teachers, researchers, health professionals, and people with RMDs.

- The EULAR School of Rheumatology represents a new era for education in RMDs.

Disclosure of Interests: None declared

DOI: 10.1136/annrheumdis-2019-eular.8503

\section{SP0066 HOW TO IMPROVE YOUR TEACHING SKILLS}

Loreto Carmona. Instituto de Salud Musculoesquelética, Research, Madrid, Spain

This is not an easy task to do in 20 minutes, but we will try to engage the attendee and to pass the message through. The most important take home message of this lecture will be that "it is the learning, not the teaching, what we must master". Good teachers are, therefore, mere facilitators of the learning process, not the stars.

This lecture will have two parts, one dedicated to teaching in general and a second one on assessment (because assessment style drives learning behaviour).

Four are the principles of teaching in medicine: 1) orientation not only to knowledge but to problem solving, 2) adaptation to needs, 3) evaluation of the efficacy of teaching, and 4) learning should be enjoyable. We will review each one of these principles and how to implement them in our daily teaching. Things like preparing a lesson plan, or tips to engage learners, will be part of this lecture.

In the second part we will outline how to improve assessment and generate good questions.

Disclosure of Interests: Loreto Carmona Grant/research support from: Abbvie Actelion, Astellas, BMS, Eisay, Gebro Pharma, Grünenthal, Leo Pharma, Lilly, MSD, Novartis, Pfizer, Roche, Sanofi-Aventis and UCB Pharma, Paid instructor for: Novartis

DOI: 10.1136/annrheumdis-2019-eular.8441

\section{THURSDAY, 13 JUNE 2019 \\ 13:30:00 - 15:00:00}

\section{Ultrasound basic I}

\section{SP0067 HOW TO ASSESS US LESIONS FOR GOUT + DEMO}

Sara Nysom. Center for Rheumatology and Spine Diseases, Rigshospitalet, Glostrup., Copenhagen Center for Arthritis Research (COPECARE), Glostrup, Denmark

Gout is the most common inflammatory joint disease in Western developed countries. Diagnosis and monitoring have historically been based upon clinical assessment combined with biochemical results (primarily p-urate) but over the last decade ultrasonography (US) has received increasing attention for these purposes. US has been shown able to detect monosodium urate deposits in both joints and tendons. In 2015 the Outcome Measures in Rheumatology (OMERACT) US Working Group developed definitions of structural lesions in gout. These include double contour sign (deposits of crystals on the surface of cartilage), tophus (larger hyper-echoic aggregation of crystals), aggregates (small hyperechoic deposits) and erosion (1). The double contour sign has been included in the ACR/EULAR 2015 gout classification criteria as a way to visualize urate deposits in joints (2). Furthermore, US can visualize potential concomitant inflammatory aspects of gout since it can visualize both joint inflammation and tenosynovitis.

In this talk the diagnostic properties of US will be described and the potential risk of false positive results due to artefacts or misinterpreted lesions will be discussed. Furthermore, the potential role of US in monitoring of treatment response will be explored.

\section{REFERENCES}

[1] Gutierrez M, Schmidt WA, Thiele RG, Keen HI, Kaeley GS, Naredo E, lagnocco A, Bruyn GA, Balint PV, Filippucci E, Mandl P, Kane D, Pineda C, Delle Sedie A, Hammer HB, Christensen R, D'Agostino MA, Terslev L; OMERACT Ultrasound Gout Task Force group. International Consensus for ultrasound lesions in gout: results of Delphi process and web-reliability exercise. Rheumatology (Oxford). 2015;54(10):1797-805.

[2] Neogi T, Jansen TLTA, Dalbeth N, Fransen J, Schumacher HR, et al. 2015 Gout Classification criteria: an American College of Rheumatology/ European Leaque Against Rheumatisme collaborative initiative. Ann Rheum Diss 2015; 74: 1789-1798.

Disclosure of Interests: None declared DOI: 10.1136/annrheumdis-2019-eular.8551 